Revista de Derecho YACHAQ N. ${ }^{\circ} 12$

Centro de Investigación de los Estudiantes de Derecho (CIED)

Universidad Nacional de San Antonio Abad del Cusco

ISSN: 2707-1197 (en linea)

ISSN: 1817-597X (impresa)

Fecha de recepción: 24/10/2020

Fecha de aceptación: 08/01/2021

[pp. 75-94]

\title{
La otra cara de los derechos humanos
}

\section{The other side of human rights}

\author{
Ubaldo Márquez Roa ${ }^{[*]}$ \\ José Eduardo García Cortés ${ }^{[*]}$
}

\begin{abstract}
Resumen: hablar de derechos humanos con una visión crítica nunca ha sido una tarea fácil, implica comprender su trasfondo filosófico antes de ir a la estructura normativa. La pandemia ocurrida durante 2020 nos ha demostrado la escasa comprensión que se tiene sobre el tema de derechos humanos. América se encuentra en un punto álgido sobre este tema, las denominadas falsas reivindicaciones jurídicas operan conforme a los intereses y circunstancias especiales de cada sociedad. Resulta de interés establecer como punto de comparación las reivindicaciones a través del denominado movimiento Black lives matter y su influencia en otros países como México, no obstante, llega en el punto de lo absurdo, al demostrar que estas reivindicaciones forman parte de la denominada sociedad del espectáculo.
\end{abstract}

Palabras Claves: derechos Humanos, Advenimiento, Efecto Floyd, Reivindicaciones jurídicas, La comercialización de los derechos humanos.

\begin{abstract}
: talking about human rights has never been an easy task, it implies to understand its philosophical background before going to normative structure. The pandemic crisis that happen during 2020 has shown us that we have a very limited understanding point of view, and we do not comprehend the issue of human rights. Nowadays America has been at a critical point of view about these rights, also we called false legal claims, due to the interests and special circumstances of each society. Although there are interests and special circumstances of each society that make them unique, whether or not we establish as a point of contrast the claims called "Black lives matter", this movement has peculiar influence in other countries such as Mexico, however, it lays in the point of absurdity, by showing these claims as part of that so-called mainstream society or society of the show.
\end{abstract}

Key words: human rights, advent, Floyd effect, Legal claims, Human rights marketing.

[*] Doctor en Derecho por la Escuela Libre de Derecho de Puebla, Docente de licenciatura y Posgrado de la Universidad de Xalapa, conferencista a nivel internacional, investigador jurídico especializado en derecho familiar. Autor de diversas obras en materia de derecho familiar, derechos humanos y filosofía del derecho.

[**] Doctor en Derecho por la Escuela Libre de Derecho de Puebla, Fundador del Instituto Nacional de Derecho Corporativo A.C. (INADECO) Abogado Certificado por ANADE. Catedrático Universitario y Autor del libro «Introducción al Derecho de los Tratados Internacionales». 


\section{DEL ADVIENTO AL ADVENIMIENTO DE LOS DERECHOS HUMANOS}

El adviento en la doctrina cristiana representa la llegada de un nuevo año litúrgico, vinculado propiamente con la venida de Jesucristo. El adviento puede reducirse a una palabra: esperanza. El advenimiento por su parte desde un campo semántico implica la llegada de alguien o algo a un lugar, cargo, posición, un suceso o acontecimiento que esta pronto a ocurrir. En el dogma y la tradición judía y cristiana implica la llegada del «Mesías», un salvador. El advenimiento puede reducirse a una sola palabra: espera.

Dentro del mundo jurídico, social y políti$\mathrm{co}$, en numerosas obras científicas, literarias, monografías, y discursos se usan los términos previamente señalados de forma romántica; como conectores de temporalidad, causalidad, consecuencia o simplemente para realizar una entonación fonética al significado que se prefiere dar a los términos que realmente pretenden utilizarse. Encontramos discursos construidos con base en esta terminología, como ejemplo se puede enunciar:

El advenimiento de la democracia...

El adviento de los derechos humanos...

El advenimiento de la modernidad...

El adviento de la posmodernidad y la globalización...

¿En el sistema jurídico mexicano, qué implicaciones conllevó el adviento y advenimiento de los derechos humanos? Debe entenderse que los derechos humanos para México llegaron como un hermoso discurso de justicia y equidad, se implantaron con altas expectativas en la mente y corazones de sus habitantes, gente que por naturaleza posee un carácter noble, pero históricamente susceptible, impresionable y manipulable. Lamentablemente, México carece de una identidad jurídica propia, siempre con de una mirada al exterior antes que al interior de su sistema jurídico, para solucionar los problemas que aquejan a su sociedad, México replica modelos administrativos, económicos, sociales y jurídicos de otros países incluso con errores tanto de forma como de fondo.

México es un país con un sistema judicial que no puede brindar una justicia pronta y expedita. En México, los juicios se ganan por desgaste y el letargo judicial, antes que por la razonabilidad de los argumentos. Lo jurídico en este país es una fórmula compleja que debe seguirse por estricta formalidad, bajo un esquema apacible y sereno al punto de ser comparado con lo inerte.

\section{EL ADVIENTO DE LOS DERECHOS HUMANOS}

Abordar el adviento de los derechos humanos no implica remontarse a los antecedentes históricos para entender sus orígenes, puntos de encuentro y su progresividad. El estudio versa sobre los avances que se han alcanzado al aplicarse dentro de los contextos jurídicos, sociales y políticos, lo cual a su vez conlleva a estudiar su contracara; el desvío en su garantía de protección y no repetición, los detractores, las violaciones sistemáticas, el exceso de ponderación, al igual que la sobre protección en la cual se ha caído por parte de los organismos y defensores de derechos humanos.

Los derechos humanos han transitado del discurso político a la integración paulatina en la legislación universal, así como, en la mayoría de las legislaciones nacionales. Catalogados como el triunfo de la razón universal, los derechos humanos se han compartido como un discurso universal respecto de las aspiraciones colectivas deseadas, plasmadas en el preámbulo de la Declaración Universal de los Derechos Humanos, la libertad, la justicia y la paz del mundo; así como el reconocimiento de la dignidad intrínseca y la igualdad entre los seres humanos. Se han vuelto la piedra angular de toda sociedad que desee autoproclamarse como democrática. 
Los derechos humanos desde el último cuarto del siglo $\mathrm{XX}$ se volvieron un discurso moral y emancipatorio destinado a combatir la discriminación, la opresión, corrupción y marginación que viven los seres humanos. Ello pone como punto de encuentro el reconocimiento de los principios relacionados intrínsecamente con el ser humano, a fin de que las autoridades de los Estados e incluso los mismos conciudadanos eviten los abusos, que dañen la libertad, la integridad, la vida y dignidad de las personas. La capitulación puede realizarse en tres directrices:

I. Los Estados deben aceptar límites al uso de su poder.

II. Los Estados deben rendir cuentas a sus conciudadanos y a la comunidad internacional por las violaciones cometidas a los derechos humanos.

III. Los Estados deben adoptar medidas necesarias para remover obstáculos a fin de que las personas gocen de plena capacidad para disfrutar los derechos promulgados y reconocidos en las distintas legislaciones del ámbito nacional e internacional.

Las directrices anteriores son fáciles de seguir o de darles la vuelta dentro de cualquier sistema jurídico.

Los derechos humanos en América Latina fueron ofrecidos bajo las premisas del discurso norteamericano y con la finalidad de consolidar un Estado Social de Derecho. Sin embargo, el contexto latino es muy diferente al norteamericano, América latina está unida por su historia, su forma de hacer política e ideología, pero dista mucho de la comprensión de sus sistemas jurídicos. Los discursos de derechos humanos, al haberse pronunciado ante sociedades fácilmente impresionables y consumistas de ideales globalizados antes que las realidades nacionales, permitió que los Estados se colocaran una soga al cuello conforme a las disposiciones e intereses del gobierno norteamericano.

Pareciera ser que el boom de los derechos humanos, surgió como una moda, antes que de la comprensión de su base filosófica. México pareciera ser que no se sale del discurso anglo-democrático programado, en este país donde aquello que se comprende o ejecuta a la mitad se considera bien hecho, es costumbre aceptada del pueblo mexicano hacer todo a la mitad o saltando algunos procedimientos; esta actitud lleva a resolver problemas de manera temporal pero no de forma permanente. El crear leyes o reformarlas a fin de establecerlas conforme a los parámetros internacionales de los derechos humanos resulta poco efectivo si no se aplican de manera que den resultados óptimos. En sociedades como la mexicana, si los cambios no son notorios al instante, tienden a ser desechados antes de dar resultados óptimos a largo plazo.

La protección a los derechos humanos bajo el principio de máxima promoción, se ha degenerado al punto de volverse una moda, las libertades básicas de las cuales todo individuo goza se dan a conocer en artículos de corte científico, literario, periodístico, por emisiones de radio televisión, podcast, discursos, en las declaraciones Miranda ${ }^{[1]}$ de los policías, así como, en las sentencias dictadas por los tribunales. Los derechos humanos se manifiestan y viven en el plano jurídico-social, no obstante, responden primero al plano científico, por crearse con base en una fórmula jurídica, mediante la cual se reconocen las libertades y obligaciones, para los gobiernos, así como para los conciudadanos de ese país. (Hübner 2015; p. 38)

[1] Lectura de la carta de derechos a las personas en el momento de su detención. 
La transición de los Estados nación a la aldea global, responde a una necesidad económica, social y jurídica, conocida como globalización. Término que conlleva la unión de los intereses comunes entre las naciones, siendo los ciudadanos los beneficiados o perjudicados por estos pactos. El término aldea global se utiliza para acuñar al mundo visto como una comunidad, la distancia y el aislamiento han sido dramáticamente reducidos por los medios de comunicación y la tecnología. (McLuhan, 2015, p. 36)

La globalización traza elementos inicialmente locales que pasan a convertirse en globales ¿Qué elementos pueden convertirse en globales? La democracia, la economía, el turismo, la religión, la política, los deportes, las regulaciones jurídicas, los derechos individuales, la comunicación, la tecnología, la educación, las formas de constituir una familia, la cultura, el arte, la seguridad, los enemigos, por mencionar algunos casi cualquier elemento que resulte capitalizable es susceptible de convertirse en un elemento global.

Las formas gobiernos trasnacionales se sustentan en tres aspectos, los cuales son: el territorio, la sostenibilidad y la planificación. (Parramón, 2015, p. 11) Los gobiernos de América Latina consolidan conforme a estos tres aspectos, más un cuarto que es el enfrentamiento a las crisis económicas. El esquema de un nuevo orden mundial, responde a la consolidación de un Estado de Derecho, pero sin especificar bajo que modalidad. Los Estados de Derecho han resultado ser una estrategia de mercado muy atractiva para la inversión extranjera. En la reflexión popular colectiva, mientras más se respeten las libertades civiles, el resto de los derechos fundamentales se encuentran mejor satisfechos. Dicha premisa es falsa, se ha adquirido socialmente como consuelo, pero dista de tener una base jurídica sólida. La premisa se reduce en garantizar «la igualdad y la libertad» bajo el grito de guerra de las masas inconformes «Derechos Humanos».

\section{EL EFECTO FLOYD Y EL ADVENIMIENTO DE LOS DERECHOS HUMANOS}

La libertad es valorada porque empodera el pensamiento, las palabras y el actuar de las personas conforme a sus deseos, no obstante, la libertad posee su vertiente positiva y negativa, conocida como liberty y freedom desde el esquema anglosajón. La igualdad provee una segunda dimensión de la libertad al requerirle una reciprocidad mutua entre los individuos. (Billy, 2019, p. 2) Ello debido a que la exigencia de libertad se vuelve una cuestión recíproca entre los individuos y sus gobiernos.

La traducción de los términos anglosajones liberty $y$ freedom responde a los sentidos negativos y positivos de la libertad respectivamente, ¿Cómo entender la dimensión de estos conceptos?:

Liberty: Libertad en un sentido negativo, implica el actuar con el apego a la norma, es decir, nuestras libertades se encuentran reguladas dentro del cuerpo jurídico-normativo, centrado propiamente en el esquema doctrinal ius positivista, lo cual se reduce a una concepción tradicional, mi derecho termina cuando comienza el tuyo.

Freedom: Libertad en un sentido positivo, atiende al principio del autogobierno del ser humano, propiamente las libertades intrínsecas que gozamos por el simple hecho de ser personas, ello se centra en el esquema doctrinal ius naturalista, por ello se entiende como la libertad sobre la esclavitud, o la libre manifestación de las ideas y la expresión, entre otras.

Ambas se encuentran reconocidas en un régimen jurídico, aplicadas erróneamente incluso por muchos defensores de derechos humanos como sinónimos, al punto de catalogar casi todo como un derecho humano. La reciprocidad que previamente se había mencionado, lamentablemente se ha vuelto una condicional ocupada por los gobiernos, así como por la población representada por los defensores de derechos humanos. Ello signi- 
fica que ambas partes (gobierno y sociedad) primero quieren recibir y posteriormente están dispuestas a dar o ceder, lo cual, conlleva a un círculo de constante inconformidad. Véase el siguiente ejemplo de algunas necesidades que principalmente en países como México se desea:

1. Respeto a sus derechos humanos

2. Tener mejores sistemas de salud, educación, seguridad pública y justicia

3. Tener mejores sueldos

4. Trabajar el tiempo justo de la jornada

5. Evitar el aumento en los insumos básicos

6. Erradicar la corrupción

Los anhelos colectivos previamente mencionados para concretarse requieren más que el pago de impuestos, sin embargo, la gente considera que, con el simple hecho de pagar impuestos, es suficiente para que el Estado garantice estos y otros servicios, al ser los órganos gubernamentales quienes se encargan de administrar el ingreso y egreso de la nación, si algo sale bien o mal, es cuestión de la administración gubernamental. Lamentablemente, lo señalado con anterioridad refleja la pobreza en la mentalidad política que países como México poseen, lo cual no es recusable a su democracia emergente.

Satisfacer los anhelos colectivos enlistados con anterioridad, garantiza un aumento en el nivel de vida de la población y la confianza en su forma de gobierno, al igual que en la ideología de sus líderes. Contar con mejores sistemas de seguridad pública y justicia, implicaría que los procedimientos judiciales sean llevados de manera correcta, el evitar un incremento en los insumos básicos, las tasas de impuestos, y mejorar el sistema educativo genera un efecto en escalada, lo cual permitiría que las personas tengan mejores oportunidades económicas para el desarrollo de su vida.

A fin de lograr la concretización de estos fines, deben preguntarse: ¿qué están dispuestos a dar para alcanzarlos? Ciertamente, cuan- do existe una falla en las disposiciones legales y gubernamentales para concretar los fines del Estado, se puede recurrir a la desobediencia de la autoridad, permitiendo que se generen parámetros para restructurar la forma de gobierno, la desobediencia civil, la acción militante y la objeción de conciencia son solo unos pequeños ejemplos de los cambios que se pueden lograr. (Ralws, 2016, p. 204)

La exigencia de libertad se vuelve una cuestión reciproca entre los individuos con sus gobiernos; los ciudadanos exigen el reconocimiento constante y la protección de los derechos humanos, porque los gobiernos en ocasiones no les han garantizado la igualdad de oportunidades, la distribución de la riqueza o la mejora en los distintos sistemas de seguridad social. Los gobiernos no pueden solventar todos estos problemas, si la población lo ha transformado en una figura paternalista, por tanto, existe una constante dependencia de la población hacia determinados programas sociales, ello genera un detrimento económico, que no le permite apostar para mejorar otros sectores de atención primaria. Ergo, se vuelve lógico el reclamo constante de sus libertades, bajo el esquema, - si no me das, al menos, no me quites aquello que ya tengo ganado-, eso implica las libertades fundamentales.

Que un Estado garantice de mejor manera las libertades civiles, no es sinónimo de que su población tenga un mejor nivel de vida. Ejemplo de ello fue lo ocurrido en Estados Unidos con George Floyd, esta persona murió a manos de la policía en Minneapolis durante la pandemia del Coronavirus en 2020. Un hombre afroamericano cuya muerte fue inmortalizada en un video celular mientras una persona pasaba por el lugar durante el atardecer del día de los caídos. Las últimas palabras de Floyd fueron I can't breathe, (no puedo respirar) tras ser sometido durante casi nueve minutos por un policía caucásico al poner su pierna sobre el cuello de Floyd. Su muerte impulsó en Estados Unidos el movimiento contra la 
brutalidad policial y la injusticia racial, bajo los eslóganes I can't breathe, y, black lives matter. (Fernández 2020)

Criterios internacionales han señalado que el uso de la fuerza que no resulte estrictamente necesario por comportamiento de la persona detenida constituye un atentado contra la dignidad humana. (Corte IDH Caso Azul Rojas Marín y otra Vs. Perú, párr. 158) La seguridad personal refiere a la protección contra las lesiones corporales, incluidas las lesiones mortales, los policías violentan el derecho a la seguridad personal cuando injustificadamente infligen lesiones corporales, independientemente de que la víctima esté o no detenida, es una obligación del Estado proteger a la población del uso excesivo de la fuerza. (Cfr. Observación: CCPR-GC-35, párr. 8)

¿Por qué tomó tanta importancia el asesinato de Floyd? Fue por las circunstancias de modo y tiempo. Las condiciones de lugar no es necesario mencionarlas, pues, en los Estados Unidos de Norteamérica es constante la violencia policiaca hacia las personas afroamericanas. Sin embargo, por la situación de la cuarentena que vivió este país a causa del SARS-CoV-2 o COVID-19, el prolongado encierro, la restricción de movilidad, la disminución del salario aunado a la pérdida del empleo en algunos casos, afectó de manera generalizada la forma en que sus habitantes realizaban su vida diaria, ello generó estrés, frustración y enojo.

La muerte de Floyd y la brutalidad policiaca fueron el detonante para la movilización social, no obstante, desde un punto de vista particular el efecto Floyd solamente sirvió como una pantalla de humo, dicho deceso, si bien fue lamentable, fungió como canal para desahogar la furia interior de los ciudadanos por el confinamiento debido al virus y los efectos económicos causados. Los norteamericanos crearon un falso mártir para un momento de desesperación como fue la crisis sanitaria. La brutalidad policiaca es un problema que desde hace mucho tiempo ha infectado a dicha so- ciedad, no obstante, ha sido la misma quien ha permitido su propio crecimiento, al partir de un esquema integrador, y no del todo inclusivo.

La sociedad norteamericana se mueve con una doble moral. Los norteamericanos han liderado la protección de los derechos civiles, para eliminar la tiranía y la opresión en el mundo, a fin de lograr instalar lo que ellos denominan verdaderos gobiernos democráticos, en los cuales se respeten las libertades fundamentales. Por naturaleza belicosos, los norteamericanos se encuentran en la constante construcción de un enemigo, es parte esencial de su historia, como ejemplos podemos mencionar a los ingleses, los españoles, las tribus de nativos como los sioux, cheyenes, cheroquis, los navajos, los mexicanos, los confederados, los alemanes, los nazis, los japoneses, los comunistas, los rusos, el Viet Cong, los coreanos, los carteles de la droga colombianos y mexicanos, el estado islámico, el califato, los grupos terroristas como AL QAEDA, ISIS, IRA, HAMAS, el gobierno chino, por mencionar algunos de la gran lista que poseen.

Construir a un enemigo es vital para cualquier nación, el enemigo reafirma la identidad, provee a las personas de un sistema de valores acordes a determinados intereses, encarna la antítesis de los valores colectivos, ya que, su creación se basa en el principio de la dualidad «blanco-negro», «bueno-malo», «bonito-feo», «lógico racional-emocional visceral», «nacional-extranjero". Los enemigos son distintos a nosotros y siguen costumbres que no son las nuestras, por lo tanto, cuando no, es preciso construirlos. (Ecco, 2011, p. 7)

La construcción del enemigo, crea la necesidad de garantizar la seguridad ciudadana a toda costa. Por ejemplo, la denotación al término pandilla, mismo que refiere a una conformación de personas con niveles de organización y estructura para la conspiración criminal más allá de su actuar en las calles (Klein, 2004, p. 57). Piénsese en la connotación del término pandilla, como un grupo de jóvenes criminales 
provenientes de zonas social-económicamente marginadas, lo cual vincula una composición racial, étnica y de color de piel determinada. Cierto es que las pandillas callejeras están estructuradas de manera flexible, con liderazgo y membresía transitorias, códigos de lealtad fácilmente trascendentes y roles informales en lugar de formales para sus miembros, cuestión que se diferencia del crimen organizado, los cuales tiene un sistema de liderazgo, estructura, contrainteligencia, códigos de lealtad, sanciones por no cumplir estos códigos, así como, experiencia empresarial que les permite el mercadeo de la droga a gran escala y la inversión del dinero obtenido. (National Gang Center 2018)

El pertenecer a una pandilla callejera y posteriormente formar parte del crimen organizado, crea el denominado efecto escalada; mismo que consiste en la repetición de ciertas conductas criminales, pero en una mayor proporción e intensidad. Véase de la siguiente manera, las pandillas callejeras se dedican a cometer crímenes tales como robo, asalto agravado, asesinato e incluso violaciones, no obstante, estos delitos se asocian a rivalidades con otras bandas y su violencia por el dominio del territorio (Ferro, 2020, p. 167). Sin embargo, en el contexto latinoamericano centrándose en México, a diferencia de la lucha entre las pandillas, el crimen organizado lucha por controlar un territorio determinado «la plaza», por lo cual su lucha no se limita a los miembros del grupo rival, también involucra al gobierno y la sociedad en general, sin embargo, muestra una réplica de la lucha por el control del territorio, a mayor escala. La escalada se refleja también en el tratamiento jurídico, pasando a ser delincuentes más peligrosos, ergo, conlleva a la aplicación de un derecho penal del enemigo antes que un derecho penal del acto.

¿Quiénes conforman estas pandillas en Estados Unidos? Como se había señalado anteriormente los grupos son conformados por núcleos de población económica desfavorecida, lo cual involucran características fenotípicas y raciales muy marcadas. En Estados
Unidos el mayor porcentaje de los miembros de pandillas pertenecen a minorías como los hispanos, los afroamericanos, siendo el $46 \%$ y $35 \%$ de esos grupos poblaciones respectivamente quienes forman parte de dichos grupos criminales, ello demuestra una brecha de segregación jurídica y social bastante considerable. (National Gang Center 2018)

El promedio del ingreso patrimonial neto en los hogares de la gente caucásica es diez veces mayor al de las personas de piel oscura, la principal tasa de pobreza en Norteamérica se encuentra entre los nativos americanos que representan el $27.6 \%$, las personas de piel oscura $26.2 \%$, y los hispanos el $23.4 \%$, mientras los caucásicos representan el $12.4 \%$ junto con los asiáticos el $12.3 \%$ (Poverty USA 2020). Bajo ese mismo esquema la población afroamericana en 2019 ocupó el 40 \% de la población penitenciaria (Human Rights Watch, 2019), durante el periodo de 2008 a 2018 la tasa de encarcelamiento había disminuido en esta población aproximadamente a un $30 \%$, mientras la de los hispanos representaba un 33 $\%$ (Zhen Zeng, 2020), curioso que durante el periodo de 2008 a 2018, durante el gobierno de Barack Obama, disminuyera la tasa de encarcelamiento de las personas afroamericana, pero no así la de los hispanos.

Lo planteado en los dos párrafos anteriores lleva a reflexionar sobre la construcción del enemigo conforme a ciertos factores fenotípicos, culturales y sociales. Las personas al pertenecer a un grupo minoritario y económicamente marginado, deciden conformar grupos de criminales a fin de obtener la riqueza, que no les ha sido equitativamente repartida. Esto genera en el resto de la población connotaciones semánticas sobre los términos criminales tales como, «pandillas» y «carteles», asimilados a un determinado grupo poblacional, por lo tanto, los términos mencionados previamente forman parte del lenguaje común asociado a la visión concreta del mensaje a transmitir, se vuelve un problema debido a que la construcción del lenguaje se ha construido por agentes 
culturales y sociales que aportan una identidad específica, es decir, desde un campo semántico-connotativo y contextual, es decir, el enemigo es peligroso porque es negro $\mathrm{y} / \mathrm{o}$ latino. Esto provoca un efecto mayor en la escalada del descontento social y garantiza el enfrentamiento directo entre los distintos sectores de la sociedad y con el gobierno.

El caso Floyd generó el efecto escalada, ello en razón del aislamiento y la crisis económica ocasionada por la pandemia, las pancartas y tablones en las tiendas comerciales con la frase black lives matter, se convirtió en una moneda de cambio, para evitar que los negocios o propiedades fueran saqueados o destruidos. Si bien el black lives matter une a personas de distintas razas, etnias y color de piel bajo un mismo eslogan e ideología, es curioso observar las imágenes en los distintos noticieros, la mayoría de la población que saquea los negocios y vandaliza los mismos son gente afroamericana o hispanos, además de ser quienes en su momento conducen el enfrentamiento con los policías antimotines en Estados Unidos. Poco importa si los líderes de estos movimientos, mencionan que fueron los miembros de distintas pandillas quienes se unieron al movimiento para causar actos de vandalismo para desacreditarlo, el daño ha sido causado y el movimiento puede ser criticado en cuanto a su seriedad.

Los derechos fundamentales de libertad de expresión, reunión y asociación hacen una triada para garantizar la democracia (Corte IDH. Caso Castañeda Gutman Vs. Estados Unidos Mexicanos, párr. 140), al materializarse de distintas formas, sea mediante la manifestación pública de las ideas, protestas o reclamos sociales, en espacios públicos como calles, plazas, parques, monumentos, o cualquier otro lugar donde puedan atraer la atención de la población. No obstante, estos derechos pueden ser objeto de restricciones compatibles con los tratados internacionales en la materia, (Corte IDH. Caso López Lone y otros Vs. Honduras Párr. 169) por ello dichas reuniones y manifestaciones deben realizarse de manera pacífica.

En Estados Unidos la primera enmienda protege la libertad de expresión en todas sus formas, dicha libertad debe ser realizada de una forma pacífica, así como la solicitud al gobierno para la reparación de agravios. La primera enmienda no protege la violencia, tampoco impone a que ningún Estado de derecho federal[ ${ }^{[2]}$, restrinja a los Estados Federales la imposición de una responsabilidad extracontractual por las pérdidas comerciales causadas por la violencia y/o por amenazas de violencia, ello debido a la libertad de jurisdicción y autonomía que posee (New York Times Co. v. Sullivan $_{2}$ 1964). Si ocurre una situación de violencia durante el ejercicio de la libertad de expresión y cuya consecuencia provoque daños, a pesar de estar protegida constitucionalmente, se debe contar con una regulación específica, para la tipificación de un hecho delictivo por la desviación de la conducta del gobernado, a fin de que los gobernados no traten de encubrirse con base en la libertad fundamental para evitar la reparación del daño. (NAACP v. Claiborne Hardware Co., 1982). Los Estados pueden imponer una sanción por los daños y las consecuencias de una conducta violenta, pero no pueden otorgar una indemnización por las consecuencias de la actividad no violenta y protegida, es decir, huelgas legalmente constituidas, reuniones, piquetes, meetings políticos en lugares específicos, siempre y cuando se respete las libertades de reunión pacífica. (Scales v. Estados Unidos, 1961)

El caso Floyd acumula el hartazgo de la sociedad norteamericana por el racismo y la desigualdad de oportunidades, el descontento hacia la política de su presidente Donald Trump, quien tenía hasta antes de la pandemia del COVID-19 el 49 \% de aprobación (EI

[2] Entendida como la Unión. 
financiero el 04/02/2020 y CNN Estados Unidos, 06/05/2020). La suma de todos estos factores llevó a que los reclamos no fuesen pacíficos, de manera inevitable se produjo una confrontación entre los manifestantes y los elementos de seguridad, variando en el grado de intensidad.

La declaración de suspensión de garantías y el uso de la guardia civil es permitida para salvaguardar el orden público en un ámbito determinado, siempre y cuando se justifiquen las prohibiciones. (Comité de Derechos Humanos. Asunto Galina Youbko c. Bielorrusia, 17 marzo 2014, párr. 9.5) La intervención de fuerzas armadas en actividades de seguridad pública como es el mantenimiento del orden público debe atender a criterios de estricta proporcionalidad, excepcionalidad y debida diligencia en la salvaguarda de las garantías, pues estas no se concilian con las funciones de las autoridades civiles. (Corte IDH. Caso Alvarado Espinoza y otros Vs. México, párr. 180) Esta labor realizada por las fuerzas armadas debe estar subordinada y ser complementaria a las labores de corporaciones civiles como son las policías, para evitar que sus labores puedan extenderse a las facultades propias de las instituciones de procuración de justicia, policía judicial o ministerial, así mismo, deben guiarse conforme a los protocolos y manuales sobre el uso de la fuerza, ello bajo los principios de excepcionalidad, proporcionalidad y absoluta necesidad, conforme con la respectiva capacitación en la materia, así como bajo supervisión de las autoridades civiles. (Corte IDH. Caso Cabrera García y Montiel Flores Vs. México párr. 86. Caso Osorio Rivera y familiares Vs. Perú. párr. 122. Caso Alvarado Espinoza y otros Vs. México. Párr. 182)

Desde los acontecimientos del día 11 de septiembre del año 2001, los norteamericanos siempre han sido temerosos, y buscan la justificación para imponer un orden, aunque ello implique un atropello momentáneo de sus libertades fundamentales. La historia y psicología social al aplicarse como un método completo y coherente para influir sobre la conducta de las personas desde un modelo social, se obtiene que la sociedad norteamericana está enfocada en la formación de líderes, así como, en la detección y neutralización de amenazas (Wood, 2015: 56). La posible existencia de una amenaza puede generar una ruptura en la forma de vida para la mayoría, lo cual impacta en su modo de percibir la realidad, misma que es una perspectiva social, bajo una construcción social emergente de la interacción entre las personas (Parales, 2020, p. 30). El anuncio y movilización de la guardia nacional para controlar los disturbios en las distintas ciudades, responde directamente a la construcción de un sistema valorativo de la cultura.

La doble moral con la cual se maneja el gobierno norteamericano es el claro ejemplo del advenimiento de los derechos humanos, se trata de una humanización-deshumanizada, así como, su contracara la deshumanización de la humanidad, ello conforme mejor convenga a los intereses del gobierno de los Estados Unidos de Norte America en la agenda interna y externa. El caso de Floyd es una muestra del esquema en el cual vive la sociedad norteamericana, la denominada post-truth o la verdad se entiende desde valores y opiniones y no desde hechos supuestamente objetivos es una apreciación ingenua de los hechos conforme al escenario político (Cambridge dictionary, 2020). El denominado reality check funciona como un mecanismo retórico por el cual quien no está de acuerdo con una versión de la verdad intenta cuestionarla y sustituirla por información sobre lo que considera verdadero (Cambridge dictionary, 2020), permitió tanto al gobierno de Donald Trump ganar terreno sobre los manifestantes para convencer sobre el despliegue de la guardia nacional, así como a los manifestantes para lograr dar un cambio en su forma de protestar y lograr que en ocasiones los policías se arrodillaran en señal de apoyo a sus propuestas para la reivindicación de los derechos civiles.

Lo señalado con anterioridad no implica que el pueblo norteamericano viva en una mentira, más bien señala que la versión del 
hecho que tienen mayor poder de convicción puede ostentarse como la verdad, y con base en esa convicción lograda en el consenso colectivo, el resto de visiones deben contrastarse. Eso involucra el adviento jurídico, que es propiamente la reivindicación de las libertades fundamentales puestas en práctica a partir de sucesos trágicos.

\section{EL EFECTO FLOYD EN MÉXICO}

México se encuentra sujeto al mainstream, no solo en aspectos culturales, también en el aspecto jurídico, principalmente en las supuestas reivindicaciones de los derechos civiles y políticos. Piénsese de la siguiente manera, en un año sin COVID-19, la muerte de Floyd hubiese sido un evento lamentable, quizá habría movilizado a las masas, pero no habría tenido el impacto que tuvo, después de una semana se hubiese olvidado, o la hubieran hecho olvidar con otras noticias, pero, como el mundo se encontraba paralizado por el virus, la noticia y los efectos que tuvo se volvieron mainstream. México es un gran consumidor de todos los productos norteamericanos, al punto de replicarlos tanto en su sociedad como en su gobierno. El caso Floyd en México tuvo su efecto de las siguientes maneras:

1) Tras la muere de Floyd, y los disturbios ocasionados por el movimiento black lives matter, la respuesta del pueblo mexicano fue manifestarse frente a la embajada norteamericana por la brutalidad policiaca en el vecino del norte.

2) La muerte de Giovanni López en Guadalajara y Alexander Martínez Gómez en el Estado de Oaxaca, a causa del presunto uso excesivo de la fuerza durante la pandemia, movilizaron a las manifestaciones de ciudadanos.

La reivindicación de derechos retoma mayor fuerza a partir de la manifestación multitudinaria, cuando las voces de muchos se vuelven una sola reclamando justicia, por ello se dice que los derechos humanos nacen de las tragedias humanas. Las reivindicaciones de derechos a través de manifestaciones pueden seguir una estrategia de mercado para hacer su reclamo asequible, aunque eso signifique llegar al punto del espectáculo y de lo ridículo.

Las manifestaciones ante la embajada norteamericana por parte de los mexicanos, reflejan el descontento del pueblo mexicano por la brutalidad que viven sus connacionales en su vecino del norte, también, es una forma para desagraviar la vieja rivalidad que siempre ha existido entre estas dos naciones. Máxime por la influencia del gobierno de Estados Unidos sobre México, lo cual, lleva a tomar políticas públicas y estrategias de gobierno similares a las de Estados Unidos. Las manifestaciones realizadas en junio del 2020 por la muerte de Giovani López por parte de la policía, comenzó con una respuesta violenta a causa de una situación violenta. (Rodríguez, Milenio 04/07/2020 y Belén, CNN Español)

La reivindicación de derechos en México durante esta época de pandemia vive del bullicio momentáneo, la falta de planeación y la tropicalización de las acciones tanto por parte del gobierno como de los manifestantes. El tratar de reprimir estas manifestaciones que no son pacíficas por medio de la fuerza crea la figura del Estado opresor. Por ello el hablar de reivindicación de las libertades fundamentales en el siglo XXI es hablar de un proceso de marketing, ello implica determinar los beneficios, la calidad, atributos, uso-aplicación, categorías del competidor. (Águeda, 2013, p. 66) Los beneficios son el ejercicio de las libertades, la calidad es la salvaguarda mediante el orden jurídico, los atributos el actuar de las autoridades conforme a las libertades fundamentales, el uso-aplicación es la interpretación jurídica de los tribunales, las categorías consisten en las maneras en que se garantizan estos derechos, sea por medio de una sentencia, una ley adjetiva, una política o programa social, el competidor en este caso es el gobierno, el cual a través de las políticas y servicios puede elevar 
la calidad de vida, y en su momento con estas permite la competencia en igualdad de circunstancias con las libertades fundamentales, ejemplo lo que sucedió en el caso Roe vs Wade.

En el caso de Alexander Martínez Gómez, quien murió al ser confundido con un delincuente en Acatlán de Pérez Figueroa, en el Estado de Oaxaca, una de las formas para tratar la indignación y la reivindicación de las libertades fundamentales fue por medio de un vídeo en el cual amigos y familiares del adolescente de dieciséis años se despidieron de su cuerpo simulando que estaban jugando un partido de futbol junto a ellos, donde de forma simbólica, anotó su último gol. (Rodríguez, Milenio, 2020) Lo planteado con anterioridad es una forma de reivindicación e indignación con base en una sociedad del espectáculo, quizá, para algunas personas le resultó conmovedor, mientras que para otros fue tomado como algo ridículo, una búsqueda para obtener algo con base en el dolor ajeno.

México es un país donde las reivindicaciones jurídicas no pueden darse de forma convergente, debido a las grandes dimensiones sociales que posee el país. Piénsese de la siguiente manera, en Estados Unidos la población penitenciaria en su mayoría está compuesta por minorías, las tasas de encarcelamiento por jurisdicción y características demográficas en penitenciarias estatales y federales, se obtiene que la población caucásica fue de 272 mientras que la de afroamericanos e hispanos fue de 1549 y 823 respectivamente. (Bronson, 2019, p. 9) México no dista mucho de esa realidad, la mala distribución de la riqueza contribuye a la creación de grupos vulnerables. Véanse los siguientes datos, el 5 $\%$ del total de la población penitenciaria era hablante de alguna lengua indígena, cifra menor al $6.5 \%$ de personas hablantes de lenguas indígenas en el país, también $4.7 \%$ de la población no sabía leer ni escribir, mientras que las características familiares de las personas privadas de libertad, $47.4 \%$ manifestó que estaba casada o vivía en unión libre, 36.9 \% re- portó que estaba soltera, mientras que el resto estaba separada o viuda. (INEGI, 2018)

La relación familia, pobreza, educación y cárcel hacen un tándem bastante relacionable para un país donde reina la desigualdad estructural, ello conlleva a que la vulnerabilidad y la inseguridad sean de una naturaleza dinámica, ecléctica y simbiótica. México está lleno de prejuicios como son; la clase social, el color de piel, la edad, el sexo, el género, por mencionar algunos, mismos que influyen en la consolidación de los puestos del poder. Estos esquemas retroalimentan la estructura social, lo cual influye en la interacción, conducta e identidad social, (Álvaro, 2007, p. 70) misma que no se crean de manera aleatoria, en México los caucásicos ganan más que las personas de piel oscura. El país sufre una situación de discriminación estructural, se repite también en el ámbito educativo, mientras más oscura sea la piel mayor será el rezago educativo, en contraposición a las personas de piel más clara. (INEGI, 2017)

En México la discriminación por color de piel y origen étnico son un tema incómodo, reflejo de un pasado inexorable que continúa vigente y permanente, una verdad de la cual se prefiere alejarse. El peor insulto para el mexicano es ser llamado «indio», dicho apelativo es sinónimo de salvaje, mugroso, moreno, poco ilustrado, reflejo de un ser vencido, doblado, arrodillado, mutilado, y humillado, es una involución en su escala social. El indio es el reflejo de una patria mutilada, un ser abnegado, pisoteado y ultrajado por cualquiera, es el hijo de la malinche, signo brutal del desprecio colectivo de una nación. Los más privilegiados económica y socialmente ejercen en mayor medida el apelativo indio a quienes son menos afortunados en razón de su color de piel aunado a la percepción de sus ingresos. «El güero-como se les denominan a las personas caucásicas es por antonomasia en la sociedad mexicana fuente de deseo, al tener una mejor posición económica y social, su aspecto físico lo pone más cerca del europeo o del norteamericano si- 
nónimos de belleza y sofisticación. Estar emparentado con la orgullosa raza del sol es motivo de vergüenza en una sociedad pigmentocráti$\mathrm{ca}^{[3]}$ como la mexicana. Con base en lo anterior puede decirse que el «ser» es entregado como un producto en interacción con los procesos de evolución en impresión y sentimientos de orgullo y vergüenza. (Serpe, 2011, p. 11)

La construcción del enemigo permite cuestionar el actuar de las autoridades y la eficacia de los derechos humanos, la experiencia del combate al enemigo da la realidad del mal, su posibilidad se funda sobre la negación de la presencia del nosotros. (Nabert, 1997, p, 106) frases como «el hombre es bueno por naturaleza, pero la sociedad lo corrompe», forman parte de la filosofía antropológica, orientada normativamente a señalar enfáticamente que el hombre es verdaderamente del telos específico de lo bueno. (Menke y Pollman, 2010, p. 94) La teoría y práctica de los derechos humanos debe evitar la antropología normativa, porque parte de esquemas muy subjetivos de la condición humana como lo hace Rousseau y Hobbes.

El estado de la naturaleza humana, se encamina hacia la agresión, lo cual es difiere de la violencia. Los Estados y los derechos humanos dentro del ordenamiento jurídico en mayor o menor medida templan dichos impulsos, para vivir bajo un determinado orden público y bienestar social. La agresión es una conducta y como tal depende, al menos de dos componentes los sustanciales y los individuales, los primeros son provocados y los segundos son las percepciones (López, 2013, p. 10), lo anterior se concreta como un estado de crisis y como se reacción ante ella. Los actos agresivos forman parte de la colectividad siguen las premisas declaradas por Ibáñez (2011, p. 142), mismas que podemos observar reflejadas en el caso Floyd:
1) Los actos agresivos no se mantienen al margen de las colectividades en las que se producen. En el caso Floyd la agresividad de las manifestaciones se reprodujo en México frente a la embajada y consulados de Estados Unidos, sin embargo, resulta curioso que en Estados Unidos no se reprodujera por parte de los norteamericanos o los mexicanos residentes en aquel país, una reacción similar por la muerte de Giovani López o por Alexander Martínez Gómez, frente a la embajada mexicana, cuando en México también existe la brutalidad policiaca.

2) Los actores implicados no tienen un perfil homogéneo y son productos de contextos sociohistóricos, que reflejan la disposición interna del Estado. Se refleja a lo largo de la historia humana, los bolcheviques, ku klux klan, los nazis y neonazis, los grupos terroristas vinculados al Estado islámico, el crimen organizado, responden a diferentes contextos, no obstante, son representantes de la crisis humanitaria, económica, política y de seguridad que los Estados viven, sus acciones solamente funcionan como meros catalizadores de esa frustración interna.

3) La interpretación del acto de violencia es contingente y depende del contexto en el que se ha producido. En efecto, las manifestaciones violentas en Estados Unidos reforzaban la necesidad de garantizar la seguridad, no obstante, a través de estas manifestaciones se logró que el presidente Trump firmara el decreto de reforma policial. (CNN consultado el 16 de junio de 2020) Estos mismos actos de violencia, provocaron la vandalización de ciertos monumentos históricos en otras partes del mundo como fue la estatua de Winston Churchill y la de Edward Colston en

[3] Término que refiere a la pigmentación de la piel, así como, los privilegios, la riqueza, las oportunidades y el goce de los derechos de las personas de acuerdo a su color. 
Londres, manifestando que eran racistas (ABC noticias consultado el 16 de junio de 2020), mientras esto mismo sucedía en Estados Unidos con las estatuas de diferentes héroes confederados, y la de Cristóbal Colón. Estos personajes históricos tenían una ideología o postura contraria a la que debe tenerse en estos días conforme al paradigma de derechos humanos que se nos ha dado, sin embargo, vandalizarlas y lograr su remoción solo implica la búsqueda del autoengaño, así como, el estar avergonzados de su historia, parecieran ser pasajes que desean olvidar, cuando en realidad deberían servir para reflexionar bajo tres aspectos:

I. La historia es escrita por los ganadores.

II. No olvidar los errores que se cometieron en el pasado para no volver a repetirlos.

III. La fuerza de una nación se refleja en sus convicciones.

El profanar los monumentos históricos reafirma lo señalado por Hannah Arendt: «Ya no podemos permitir recoger del pasado lo que era bueno y denominarlo como nuestra herencia, despreciar lo malo y considerarlo simplemente como un peso muerto que el tiempo por si mismos enterrará en el olvido». (1951, p. 71)

4) La agresividad y la violencia no son ejercicios vacíos sin que estén dotados de significado y sentido. Las movilizaciones violentas lamentablemente traen en ocasiones resultados rápidos, pero con cierta reticencia y resentimiento. Por ejemplo, las grandes masacres que han existido a lo largo de la humanidad como el holocausto judío los genocidios de Ruanda, Exyugoslavia, Kosovo entre otros, a partir de estos actos de violencia extrema, los derechos humanos y libertades fundamentales fueron reivindicados, para la consolidación del derecho internacional de los derechos humanos y el derecho internacional humanitario. No obstante, esta misma agresividad pudo verse aplicada desde el ámbito judicial, ejemplo de ello fueron los tribunales Israelitas para juzgar a los criminales nazis, los cuales operaban bajo la zona gris del derecho internacional, bajo cierta tolerancia de la comunidad internacional como tribunales ad hoc, pero de manera encubierta respondían a una situación relacionada con la violencia y la venganza que sentía el pueblo judío hacía los partidarios nazis.

Todo lo señalado en los anteriores párrafos representa la adquisición ideológica que México ha recibido de su país vecino del Norte, retomar la visión violenta y agresiva del ser humano, así como, la construcción del enemigo genera el punto de quiebre entre las demandas de reivindicación, el proteccionismo y sobre proteccionismo de estos derechos humanos. El advenimiento de los derechos humanos en México ha generado una comercialización de estas libertades fundamentales y lleva al sistema judicial mexicano a una excesiva ponderación de derechos, confundiendo la máxima protección de las libertades fundamentales con la obtención de una respuesta favorable a las pretensiones de los interesados. (Jurisprudencia de registro 2004748, 2013)

La comercialización de los derechos humanos se ha producido bajo un ambiente óptimo para la competencia de mercado, véase de la siguiente manera, como ciudadanos demandamos seguridad, ya sea que la brinde el Estado por medio de sus cuerpos policiacos o que se permita a los ciudadanos la portación de un arma de fuego como es el caso de Estados Unidos, en ambos esquemas nos encontramos ante un sistema garantista. Sin embargo, dentro este esquema, existe una competencia por garantizar la seguridad como un derecho humano sea por parte del Estado o bien por los particulares a través de su actuar colectivo o dentro del sector privado. Ejemplo de ello resulta la policía nodal, la naturaleza y 
funcionamiento de una empresa de seguridad, cumple con brindar seguridad a quienes los contratan, en países como México el esquema se repitió con la creación de la guardia civil, la cual se equipará como una fuerza policiaca (García, 2019, p. 30), estos cuerpos de seguridad generaron una gran confianza de los ciudadanos en contraste a la confianza que tienen sobre la policía municipal, en lugares como Monterrey la fuerza civil ha tenido una gran efectividad para el combate al crimen organizado. (Avant, 2019, p. 161)

El efecto Floyd en México refiere a la brutalidad policiaca, aunado al precario sistema de seguridad, la desidia de buscar una reivindicación de las libertades fundamentales, y la preferencia por tener una sociedad del espectáculo antes que una verdadera crítica a las instituciones gubernamentales. México es un país que sufre de un conformismo jurídico, pues basta con creer que por tener los derechos humanos consagrados en distintos ordenamientos jurídicos y realizar una interpretación de los mismos por parte de las autoridades jurisdiccionales, esas libertades se encuentran protegidas. México en materia jurídica, política, económica, y social se encuentra a la expectativa de los gobiernos norteamericanos y europeos, pues busca replicar las interpretaciones jurídicas, políticas públicas y modelos de comportamiento social para sentirse que ha transitado a un plano más civilizado a la american way of life, por tanto, se vive de momentos aislados en la protección de las libertades fundamentales.

\section{A MAYOR DEMOCRACIA MENOR TRIUNFO ECONÓMICO}

Los derechos humanos en México han sido una moneda de cambio, al poseer una economía emergente requiere de préstamos internacionales, la manera más fácil de obtener estos préstamos es por medio de la firma de tratados internacionales. La errónea fórmula jurídico-política catalogada como: «A mayor democracia, mayor protección de los Derechos
Humanos, mejores oportunidades de desarrollo económico, y bienestar social», no funciona para México en siglo XXI, pues los avances que no se lograron en materia democrática durante el siglo XX no van a poder lograrse en esta época. Véase la ruta de la seda, países como China, no poseen regímenes democráticos y son catalogados de autoritarios, pero, tienen más éxito comercial, además, prestan dinero a las economías emergentes, sin importar su forma de gobierno, su desarrollo en la protección de los derechos humanos o la corrupción.

El esquema de competencia económica oriental se basa propiamente en demostrar que es posible el triunfo sin satisfacer las ilusiones democráticas dictadas por la Unión Europea y los Estados Unidos. Véase el caso mexicano el cual es uno de los diez países con mayor deuda externa en el mundo. Todos los préstamos internacionales que se le han otorgado a México han sido para cumplir con los principios de la justicia social que señalaba John Rawls. Sin embargo, esto no ha dado el resultado deseado, si se presta atención en las estadísticas de la Comisión Interamericana de Derechos Humanos en el año 2019, la Comisión en relación con el Estado mexicano tuvo 695 peticiones recibidas del estado mexicano, 744 peticiones pendientes de estudio inicial, 101 peticiones abiertas y 941 no abiertas a trámite, 932 peticiones y casos en trámite (fondo y admisibilidad), se emitieron 10 informes de admisibilidad y 1 de inadmisibilidad, 55 informes de archivos, 3 informes de soluciones amistosas, 1 caso enviado a la Corte, 186 solicitudes de medidas cautelares de las cuales 4 se otorgaron. Sin contar el caso enviado a la Corte Interamericana, se obtiene la sumatoria de los 3603 asuntos vinculados con derechos humanos, además de los acumulados de años anteriores. (CIDH consultado el 13 de junio de 2020)

Los datos señalados en el párrafo anterior, generan una serie de interrogantes respecto a este país, preguntas tales como: ¿Qué está pasando con su sistema de justicia? ¿Cómo se 
está manejando el dinero prestado para consolidar la democracia? ¿Qué sucede con la formula supuestamente efectiva "a mayor democracia, mayor protección de los Derechos Humanos, mejores oportunidades de desarrollo económi$\mathrm{co}, \mathrm{y}$ bienestar social"? Todo pareciera indicar que es una mentira. ¿Dónde está el error? Muchos podrán señalar como respuesta a la corrupción, pero, esta respuesta es muy ambigua, en teoría México de manera legal y fáctica posee un sistema nacional anticorrupción, tiene 5 mil 491 programas y acciones de desarrollo, no obstante, su nivel de desigualdad económica no decrece, sino que se incrementa. (CONEVAL, consultado el 13 de junio de 2020)

Las condiciones de estos empréstitos solicitados a los organismos internacionales, sirven para garantizar que el país sea capaz de reembolsar los recursos al ente internacional, esos recursos pueden ponerse a disposición de otros países miembros que los necesiten. Los Estados tienen la obligación de realizar acciones preventivas, criterios de ejecución cuantitativa, metas indicativas, y la ejecución estructural. (Driscoll, 2015, p.56) Los programas presentados por el Estado mexicano no resultan eficaces, en algunas ocasiones no logran cubrir la deuda, o bien cubren el inicio pero no generan el desarrollo sustentable esperado para el resto de su población, ya que el gobierno crea los atractivos de inversión, es decir las reformas legales, el plan de la obra, y los programas de licitación, pero las condiciones de inversión, la estructura, y el desarrollo queda delegado a las empresas privadas, sean nacionales o trasnacionales, las cuales al ganar las licitaciones, conservan la concesión y por ende los réditos producidos, en ese sentido recuperan la inversión y obtienen la ganancia. Siendo así, la denominada inversión para el empleo, en realidad si se cumple, no obstante, el gobierno no muestra es que esos empleos creados forman parte del sector de la subcontratación por obra temporal, estos trabajadores son explotados laboralmente y terminada la obra vuelven a ser desempleados, o en el mejor de los casos pasan a formar parte de la economía informal. De manera que el combate a la pobreza no disminuye, en ese sentido el sistema monetario internacional, profundiza la desigualdad del desarrollo entre las naciones, en particular entre las denominadas y las imperialistas. (Serulle, 1984, p. 9)

En el caso mexicano, en el 2018 se detectó que el 21.9 \% de la población, el equivalente a 27.4 millones de personas se considera como el núcleo de la población no pobre y no vulnerable, mientras que los pobres y grupos vulnerables representan el $72.6 \%$ de la población, lo equivalente a 107 millones de personas. (CONEVAL 9 de junio de 2020) De manera que los empréstitos solicitados a los organismos internacionales, y, los programas que se implementan respecto a estos, en realidad no son fructíferos. México posee una deuda externa, de 452 mil 991 millones de dólares, lo equivalente al $35.8 \%$ de su producto interno bruto. (World Bank Group 14 de agosto de 2020)

China ha prestado dinero a países en América latina tales como; Venezuela, Brasil, Ecuador, Argentina y Bolivia (BBC News Mundo consultado 4 de junio de 2020) los cuales al igual que México poseen violaciones constantes a los derechos humanos, sus gobiernos democráticos son catalogados como corruptos, por ejemplo, Venezuela, ante transparencia internacional es catalogado como el país más corrupto de América Latina y con una crisis humanitaria producida por la corrupción, no obstante alcanza préstamos internacionales por parte del gigante comercial asiático. (Transparencia Internacional consultado el 1 de enero de 2020) China ha demostrado que a menor democracia mayores son los triunfos económicos en el siglo XXI.

El gobierno chino y las empresas trasnacionales comprenden que la hegemonía mundial gira en tres posiciones esenciales, la político-militar, la económica y la cultura. (Ceceña, 1995, p. 541) Las relaciones hegemónicas del gobierno chino se construyen con relación a 
las esferas y relaciones esenciales, para garantizar un posicionamiento en las telecomunicaciones, los energéticos, materias primas, alimentos de consumo generalizado y fuerza de trabajo. China sabe desenvolverse en estas áreas de impacto, en 2019 las empresas con mayor impacto económico eran Waltmart, Sinopec Group, Royal Dutch Shell, China National Petroleum, State Gird, tres de ellas son chinas, en contraposición a la anglo-neerlandesa y norteamericana (BBC News Mundo consultado el 14 de julio de 2020). En el primer semestre de 2020 las empresas más valiosas del mundo eran 1) Saudi Aramco, 2) Microsoft, 3) Apple, 4) Amazon inc, 5) Alphabet inc, 6) Facebook, 7) Alibaba group, 8) Tencent, 9) Berkshire Hathaway inc, 10) Johnson \& Johnson, (FXSSI consultado el 14 de agosto de 2020) como se puede apreciar en el número siete y ocho son empresas chinas dedicadas a las telecomunicaciones, por lo que a pesar del virus que ataco a la humanidad durante el 2020 y frenó a gran parte de la economía mundial, las empresas chinas mantienen una posición estable en la economía mundial. Destáquese que existe una asimetría territorial entre los territorios continuos de los Estados y los territorios discontinuos de las corporaciones transnacionales, las cuales persiguen estrategias de integración global, lo cual permite la competencia del libre mercado. (Dicken, 2015, p. 233)

China ha consolidado su influencia en el siglo XXI, gracias a la política del consenso de Beijing (Sanz, 2013, p. 146) mediante la cual postula como ejes torales:

1) Reforma incremental.

2) Innovación y experimentación.

3) Crecimiento basado en las exportaciones. de la demanda externa.

4) Capitalismo de estado.

5) Autoritarismo.

China no sigue los patrones presentados por los gobiernos occidentales, no sigue la formula a la cual se le ha hecho hincapié con an- terioridad. Porque no es rentable en su aspecto social, económico y político, debido a que posee 1.395.380.000 millones de habitantes, lo cual hace imposible de ejecutar.

Muchos de los estudios de los paradigmas de derechos humanos en las naciones con economías emergentes, no aceptan el conceso ya que se tiene miedo a la disminución y pérdida de los progresos en derechos humanos. Es válido por tanto preguntarse de forma retórica ¿Cuándo ha servido pactar con la tiranía para salvaguardar las libertades fundamentales? Sin embargo, habría que preguntarse de igual manera ¿Si la democracia realmente garantiza en el siglo XXI, la efectividad de las libertades fundamentales y el crecimiento económico en México? La respuesta para ambos cuestionamientos es una negación, México vivió durante 300 años como un virreinato de España, posteriormente tuvo un imperio efímero fundado por Iturbide, una dictadura con Antonio López de Santa Anna, una guerra civil conocida como la guerra de reforma en la cual había una república errante con Benito Juárez, al mismo tiempo que un imperio con Maximiliano de Habsburgo, después una dictadura con Porfirio Diaz, una revolución en 1910, una guerra cristera, la consolidación de una república democrática con Lázaro Cárdenas la cual durante setenta años fue gobernada por un partido hegemónico y finalmente en el año dos mil México realizó el cambio de gobierno y partido con Vicente Fox. Siguiendo esa línea de ideas México lleva realmente 20 años como una verdadera república democrática y durante este periodo el país ha vivido una denominada guerra contra el narcotráfico que lo ha llevado a un punto muy endeble sobre su forma de gobierno y a sus crisis económicas. Podría pensarse que no se pueden interponer los intereses económicos antes que las libertades fundamentales, ambas cuestiones deben ir de la mano para lograr el éxito, no obstante, dicha premisa también es una falsa, volvamos a ver a China, se ha visto beneficiada siguiendo un modelo más autoritario y menos democrático. 


\section{CONCLUSIONES}

1. Hablar del adviento y advenimiento de los derechos humanos resulta ser la eterna espera, el sueño de los justos. Es partir de un esquema filosófico, y su constante búsqueda por la materialización en su cuerpo jurídico, sin una dimensión de las consecuencias jurídicas, políticas y económicas de los Estados.

2. Los derechos humanos han pasado a ser una moda, se encuentran lejos de la base filosófica, aún más de su plano científico. El Estado mexicano basa su interpretación conforme a los aspectos globales. Cierto es que los derechos humanos crean los denominados estados de derecho, no obstante, esto resulta ser una estrategia de mercado muy atractiva para la inversión extranjera. La denominada garantía de protección resulta falsa, ya que no se crean bases sólidas para su reclamo.

3. El problema con las reivindicaciones de los derechos humanos, son los mismos seres humanos, la gente está acostumbrada a exigir y recibir, pero evitar en la mayor medida de lo posible el dar. Floyd, lo demostró, ahora se ha vuelto un mártir innecesario, pero al final un mártir, que se mueve en una sociedad con doble moral.

4. A México le encanta copiar esquemas, sin saber el cómo, el por qué o las consecuencias. El mexicano utiliza cualquier pretexto para inconformarse, sin mirar de lleno su realidad.

5. México debe reflexionar y determinar la proyección de sus decisiones en la política internacional, lamentablemente aumentar su proyección económica no siempre va de la mano con el garantizar las libertades individuales, a la larga crea un esquema rentable. En México se vive bajo un esquema democrático que no han producido avances significativos.

\section{REFERENCIAS}

Álvaro Estramiana J. L. (2007) Introducción a la psicología social sociológica. Barcelona, Editorial UOC.

Avant D, Berry M, Chenoweth E, et al (2019) Civil action and the dynamics of violence. United States of America, Oxford University Press.

Arendt H. (1951). Los orígenes del totalitarismo, España, Titivillus.

Águeda Esteban T, Mondéjar Jiménez J.A, (2013) Fundamentos de Marketing España Business Marketing School.

Bragg B, (2019) The three dimensions of freedom, editorial Faber \& Faber social, Boston.

Bronson J, Carson Ann Ph. D. (April 2019) Prisoners in 2017 BJS, U.S. Departament of Justice Office of Justice Programs Bureau of Justice Staticis, NCJ 252156.

Recuperado de http://dl.icdst.org/pdfs/files3/54d 0651293417aac529c2ce69c4e4efc.pdf

Cambridge Dictionary, Recuperado de https:// dictionary.cambridge.org/es/diccionario/ingles/post-truth?q=Post-truth

Cambridge Dictionary Recuperado de https:// dictionary.cambridge.org/es-LA/dictionary/ english/reality-check

Ceceña, A. \& Barreda, A. (1995). Producción estratégica y hegemonía mundial. México: Siglo XXI.

Dicken, P. (2015). Global Shift. Mapping the changing contours of the world economy. Londres: Guilford Press.

Driscoll D. (2015). ¿Qué es el fondo monetario internacional? Washington Departamento de relaciones externas, Fondo monetario internacional.

Eco, U. (2011). Construir al Enemigo, (Trad. Helena Lozano Miralles) España, editorial Titivillus.

García Ruiz, I. (2019). Guardias civiles, ciudadanos de uniforme en busca de derechos: 2008-2018: el relato de la lucha por la digni- 
dad socio-laboral de los trabajadores de la Benemérita, narrado por sus propios protagonistas. España, Editorial Almuraza.

Hübner Gallo, Jorge Iván. (2015). Los derechos humanos: Historia, fundamento, efectividad. Chile. Editorial Jurídica Chile.

Ibáñez García, T. (2011). Introducción a la psicología social. Barcelona, Editorial UOC.

Instituto Nacional de Estadística y Geografía. (enero-marzo 2018) En números, características de la población privada de la libertad en México documento de análisis y estadísticas, Instituto Nacional de Estadística y Geógrafa, Vol. 1 número 12, recuperado de http://internet.contenidos.inegi.org.mx/ contenidos/Productos/prod_serv/contenidos/espanol/bvinegi/productos/nueva_estruc/702825101176.pdf

López Díaz, L. M. y Vadillo Olmo F. J. (2013). Agresividad y violencia en epilepsia. España, Editorial Club Universitario.

Sanz J. (Enero / Marzo 2013). La influencia de China en Latinoamérica: el consenso de Washington y el de Beijing, Cuadernos de Pensamiento Político, N. ${ }^{\circ} 37$.

Serulle J., Boin J. (1984). Fondo monetario internacional, deuda externa y crisis mundial, Madrid, lepola.

Nabert J. (1997). Ensayo sobre el mal, Madrid, Caparrós editores.

Mcluhan Marshall, Powers Bruce. (2015). La aldea global: Transformaciones en la vida y los medios de comunicación en el siglo XXI: La globalización del entorno: Último trabajo de Marshall McLuhan. España, Gedisa.

Menke Christoph y Pollman Arnd. (2010). Filosofía de los derechos humanos, España, editorial Herder.

Parales Quenza, Carlos José. (2020). Psicología social: Un acercamiento histórico al estudio de las relaciones sociales, Colombia, Editorial GEDISA.
Parramón J. (2015). Una alternativa al capitalismo neoliberal, editorial club universitario.

Wood Gordon, S. (2015). La revolución norteamericana, México, Pengüin Random House.

Zhen Z., Ph.D. (March 2020). BJS Statistician, Jail Inmates in 2018 U.S. Department of Justice Office of Justice Programs Bureau of Justice Statistics, NCJ 253044, recuperado de https:// www.bjs.gov/content/pub/pdf/ji18_sum.pdf

\section{REFERENCIAS JURÍDICAS}

\section{Jurisprudencia internacional}

Corte IDH. Caso Salvador Chiriboga Vs. Ecuador. Excepción Preliminar y Fondo. Sentencia de 6 de mayo de 2008. Serie C N. 179.

Corte IDH. Caso Alvarado Espinoza y otros Vs. México. Fondo, Reparaciones y Costas. Sentencia de 28 de noviembre de 2018. Serie $\mathrm{CN}^{\circ} 370$.

Corte IDH Caso Cabrera García y Montiel Flores Vs. México, Excepción Preliminar, Fondo, Reparaciones y Costas. Sentencia de 26 de noviembre de 2010. Serie C N. ${ }^{\circ} 220$.

Corte IDH Caso Osorio Rivera y familiares Vs. Perú. Excepciones Preliminares, Fondo, Reparaciones y Costas. Sentencia de 26 de noviembre de 2013. Serie C N. ${ }^{\circ} 274$.

Corte IDH. Caso Castañeda Gutman Vs. Estados Unidos Mexicanos. Excepciones Preliminares, Fondo, Reparaciones y Costas. Sentencia de 6 de agosto de 2008. Serie C N. ${ }^{\circ} 184$.

Corte IDH. Caso Alvarado Espinoza y otros Vs. México. Fondo, Reparaciones y Costas. Sentencia de 28 de noviembre de 2018. Serie $\mathrm{C} \mathrm{N} .{ }^{\circ} 370$.

Corte IDH. Caso López Lone y otros Vs. Honduras. Excepción Preliminar, Fondo, Reparaciones y Costas. Sentencia de 5 de octubre de 2015. Serie C N. ${ }^{\circ} 302$.

Corte IDH Caso Azul Rojas Marín y otra Vs. Perú. Excepciones Preliminares, Fondo, Repara- 
ciones y Costas. Sentencia de 12 de marzo de 2020. Serie C N. ${ }^{\circ} 402$.

Observación: CCPR-GC-35 Libertad y seguridad personales (Sustituye la CCPR/GC/8)

Comité de DH. Asunto Galina Youbko c. Bielorrusia, 17 marzo 2014.

\section{Jurisprudencia de Estados Unidos}

Lynch v. Estados Unidos, 292 US 571, 581 (1934).

Scales v. Estados Unidos, 367 US 203 (1961).

New York Times Co. v. Sullivan 376 US 254 (1964).

NAACP v. Claiborne Hardware Co., 458 US 886, 907-08 (1982).

\section{Jurisprudencia Mexicana}

Jurisprudencia de registro 2004748 [Octubre de 2013] https://sjf.scjn.gob.mx/SJFSist/Paginas/DetalleGeneralV2.aspx?Epoca $=1 \mathrm{e} 3 \mathrm{e}$ $10000000000 \&$ Apendice $=100000000000$ 0\&Exresion $=2004748 \&$ Dominio $=$ Rubro, Texto\&TA_TJ $=2 \&$ Orden $=1 \&$ Clase $=$ Detall eTesisBL\&NumTE $=1 \& E p p=20 \&$ Desde $=$ $100 \&$ Hasta $=-100 \&$ Index $=0 \&$ InstanciasSele ccionadas $=6,1,2,50,7 \& I D=2004748 \& \mathrm{Hit}=1$ $\& I D s=2004748 \&$ tipoTesis $=\&$ Semanario $=0$ $\&$ tabla $=\&$ Referencia $=\&$ Tema $=$

\section{Fuentes de internet}

Comisión Interamericana de Derechos Humanos, Estadísticas por país, informe anual 2019 recuperado de http://www.oas.org/es/cidh/multimedia/estadisticas/estadisticas.html\#porpais consultado el 13 de junio de 2020

CONEVAL (2019) medición de la pobreza de 2008-2018 Estados Unidos Mexicanos, recuperado de https://www.coneval.org.mx/ Medicion/Paginas/Pobrezalnicio.aspx

FXSSI (2020) Las empresas más valiosas del mundo, recuperado de https://es.fxssi.com/ las-empresas-mas-valiosas-del-mundo
National Gang Center, (2018) Race/ethnicity of gang members recuperado de https://www. nationalgangcenter.gov/Survey-Analysis/ Demographics

Serpe R, Stryker S. (2011) The symbolic interactionist perspective and identity theory. Publish, recuperado de https://www.researchgate.net/ publication/227038933_The_Symbolic_Interactionist_Perspective_and_Identity_Theory

Transparencia Internacional, (2019) índice de percepción de la corrupción 2019, recuperado de http://www.rendircuentas.org/indice-percepcion-la-corrupcion-2019/

World Bank Group, (2020) International debt statistics 2020, Washington, Theworld bankgroup, https:// openknowledge.worldbank.org/bitstream/ handle/10986/32382/9781464814617.pdf

\section{Hemerografía}

Barría C. (2019). Fortune 500: cómo hizo China para sobrepasar a EE. UU. en el ranking de las compañías más grandes del mundo (y qué tiene que ver los «zombis gigantes» BBC News Mundo Recuperado de https:// www.bbc.com/mundo/noticias-49101744

Belén, Z. (2020). Segunda semana de protestas por caso Giovanni en Guadalajara. CNN Español. recuperado de https://cnnespanol. cnn.com/video/giovanni-protestas-abusopolicia-muerte-jalisco-membrillos-perspectivas-mexico-cnne-belen-zapata/

Bloomberg, A. W. (2020). Trump alcanza $49 \%$ de aprobación en EE. UU., el nivel más alto desde que inició su mandato. El financiero. Recuperado de https://www.elfinanciero. com.mx/mundo/trump-alcanza-49-de-aprobacion-en-eu-el-nivel-mas-alto-desde-queinicio-su-mandato

Kevin Liptak. (2020). Trump firma decreto de reforma policial y ofrece una defensa a pleno pulmón de la policía, CNN. Recuperado de https:// cnnespanol.cnn.com/2020/06/16/trump-firma- 
decreto-de-reforma-policial-y-ofrece-una-defensa-a-pleno-pulmon-de-la-policia/

Milenio. (2020). Manifestantes vandalizan estatuas de Colón en EE. UU. contra el colonialismo Milenio. Recuperado de https://www. publico.es/internacional/protestas-estadosunidos-manifestantes-vandalizan-estatuascolon-eeuu-colonialismo.html

Orgaz, C. J. (2019). Cuáles son los países de América Latina que más dinero le deben a China (y qué implicaciones tiene esa deuda) BBC News Mundo recuperado de https:// www.bbc.com/mundo/noticias-america-latina-50574118

Rodríguez, F. y Calvillo, M. (2020). Protestan en Guadalajara por muerte de Giovanni López; queman patrullas. Milenio Digital recuperado de https://www.milenio.com/estados/giovanni-lopez-protestas-asesinato-joven-jalisco

Rodríguez, O. (2020). Policías confunden a joven con delincuente y lo matan en Oaxaca, Milenio. recuperado de https://www.milenio. com/estados/oaxaca-acusan-policias-disparar-joven-alexander-martinez

Salazar, Ivannia (2020). Cubren con tablones las estatuas de Churchill, Mandela o Gandhi en Londres para que no sean vandalizadas. ABC noticias. recuperado de https:// www.abc.es/internacional/abci-cubrentablones-estatuas-churchill-mandela-ogandhi-londres-para-no-sean-vandalizadas-202006121247_noticia.html 